\title{
Development and Parametric Evaluation of a Tabulated Chemistry Tool for the Simulation of n-Heptane Low-Temperature Oxidation and Autoignition Phenomena
}

\author{
George Vourliotakis, Dionysios I. Kolaitis, and Maria A. Founti \\ Laboratory of Heterogeneous Mixtures and Combustion Systems, Thermal Engineering Section, School of Mechanical Engineering, \\ National Technical University of Athens, 9 Heroon Polytechniou Street, Polytechnioupoli Zografou, 15780 Athens, Greece
}

Correspondence should be addressed to Dionysios I. Kolaitis; dkol@central.ntua.gr

Received 30 December 2013; Revised 8 May 2014; Accepted 9 May 2014; Published 10 June 2014

Academic Editor: Michael Fairweather

Copyright (C) 2014 George Vourliotakis et al. This is an open access article distributed under the Creative Commons Attribution License, which permits unrestricted use, distribution, and reproduction in any medium, provided the original work is properly cited.

\begin{abstract}
Accurate modelling of preignition chemical phenomena requires a detailed description of the respective low-temperature oxidative reactions. Motivated by the need to simulate a diesel oil spray evaporation device operating in the "stabilized" cool flame regime, a "tabulated chemistry" tool is formulated and evaluated. The tool is constructed by performing a large number of kinetic simulations, using the perfectly stirred reactor assumption. n-Heptane is used as a surrogate fuel for diesel oil and a detailed n-heptane mechanism is utilized. Three independent parameters (temperature, fuel concentration, and residence time) are used, spanning both the low-temperature oxidation and the autoignition regimes. Simulation results for heat release rates, fuel consumption and stable or intermediate species production are used to assess the impact of the independent parameters on the system's thermochemical behaviour. Results provide the physical and chemical insight needed to evaluate the performance of the tool when incorporated in a CFD code. Multidimensional thermochemical behaviour "maps" are created, demonstrating that cool flame activity is favoured under fuel-rich conditions and that cool flame temperature boundaries are extended with increasing fuel concentration or residence time.
\end{abstract}

\section{Introduction}

The prevailing kinetic mechanisms governing the oxidative reactions of hydrocarbon fuels are continuously changing depending on the temperature of the mixture. In this context, it is possible to define low-, intermediate-, and high-temperature oxidative regions, in which significantly different oxidizing schemes are effective [1-3]; each oxidative region can be described by a different subgroup of elementary chemical reactions. However, for the majority of the most commonly used fuels, comprehensive chemical kinetics mechanisms, capable of describing the complete thermochemical behaviour in all three oxidative regions are currently not available. As a result, in detailed computational fluid dynamics (CFD) simulations of conventional combustion systems, it is common practice to effectively describe the high-temperature oxidative region, which is the most important in terms of heat release and pollutant formation [3]. However, there are specific applications, where the low- and intermediate-temperature oxidative regions become important, for example, homogeneous charge compression ignition (HCCI) internal combustion engines (ICE) [4-6], lean premixed prevaporized (LPP) combustors in gas turbines $[7,8]$, and liquid fuel reformers for fuel cell applications [9-11] or industrial safety $[12,13]$; in these cases, cool flame reactions largely determine the overall reactivity and have to be taken into account.

The term "cool flame" is conventionally used to collectively describe the low- and intermediate-temperature (approximately $500 \mathrm{~K}-900 \mathrm{~K}$ ) oxidative preignition reactions emerging in reactive systems fed with organic fuels, such as saturated and unsaturated hydrocarbons, alcohols, aldehydes, ketones, acids, oils, ethers, and waxes $[13,14]$. Cool flame reactions are modestly exothermic; they are often described 
as partial or intermediate oxidation reactions, since they result in the formation of a large variety of long-lived intermediate species (e.g., alcohols, acids, aldehydes, and peroxides) [14-16]. Cool flames occur preferentially under fuel-rich conditions [17] and are characterized by the appearance of a faint bluish light, which is attributed to the chemiluminescence of excited formaldehyde [18]. Cool flames appear in the form of a self-quenching temperature and pressure pulse, during the two-stage ignition, and are associated with the "ignition delay time" phenomenon, as well as "knocking" phenomena in spark-ignition ICE $[15,19]$.

The cool flame oxidation region is characterized by a competition between chain-termination and chainbranching reactions $[15,19]$. At lower temperatures, chainbranching reactions are favoured, leading to the acceleration of the overall reaction rate. When the temperature is increased, the decomposition of chain-branching precursors is enhanced; in contrast, chain-termination reactions become more important, since their activation energy is decreasing with increasing temperature. As a result, a negative temperature coefficient (NTC) region emerges in the temperature regime where transition between the lowand intermediate-temperature oxidative mechanisms occurs. In the NTC region, the overall reaction rate is decreasing with increasing temperature; this behaviour is a distinctive characteristic of cool flame reactions. Cool flame reactions can be "stabilized" when a technical device operates in the NTC region. In this case, the heat losses through the device boundaries are fully compensated by the heat release of the exothermal cool flame reactions; the device achieves steady-state operation, which is not accompanied by thermal ignition [20]. The utilization of such innovative stabilized cool flame (SCF) reactors allows better control over the combustion process in liquid fuel premixed combustion systems; they can also be used to assist liquid fuel (e.g., diesel oil) reforming to a hydrogen-rich gas for fuel cell applications [9-11].

In order to describe in sufficient detail the degenerate chain-branching cool flame oxidative activity leading to the NTC behaviour, multistep detailed chemical kinetics mechanisms have to be used [19, 21-28]. Due to the high computational costs associated with implementing detailed chemical kinetic mechanisms in multiphase CFD tools [29], cool flames are usually neglected in detailed CFD simulations of turbulent reactive flows. In the context of numerical simulations of reactive systems, cool flame reactions are commonly described using simplified zero- or one-dimensional modelling tools [22, 23, 30, 31].

Motivated by the need to numerically simulate the turbulent, multiphase, multicomponent, and reactive flowfield developing in a non-igniting SCF technical device, the authors have developed a variety of alternative modelling techniques [24, 32-35], aiming to reduce the heavy computational load imposed by the implementation of detailed kinetic schemes into CFD solver. As a part of this ongoing work, the present study focuses on the development of a "tabulated chemistry" modelling approach, capable of simulating the thermochemical behaviour of n-heptane in the low-temperature oxidation and autoignition regimes.
The development of the "tabulated chemistry" tool focuses on accuracy and ease of implementation in multiphase CFD codes. In contrast to a previous "tabulated chemistry" approach developed by the authors [34], which focused solely on the SCF regime, the tool presented in this work is capable of describing the entire low- and intermediate-temperature oxidation regions, including autoignition phenomena. The latter are important in technical devices, where ignition must be prevented. Furthermore, the proposed tool provides information for important species concentrations, which is essential for accurate prediction of the reformate mixture composition in fuel cell reforming applications. In addition to the development of the "tabulated chemistry" tool, the obtained numerical results are used to evaluate the impact of varying significant operational parameters on the thermochemical behaviour of the system. Therefore, the main scope of this study is two-fold, that is, to develop a simulation tool (tabulated chemistry) and to thoroughly investigate the thermochemical behaviour of $n$-heptane, by highlighting and explaining the physical and chemical underlying phenomena (e.g., through sensitivity analysis). The latter is a critical step prior to the implementation of the developed tool in a CFD code.

\section{Numerical Simulations}

The developed "tabulated chemistry" tool is focused on the simulation of technical devices using diesel oil fuel, which is essentially a mixture of a large variety of organic species; the exact composition of the commercially available diesel oil fuel mixture varies significantly, depending on the raw fuel source and refinement processes. As a result, detailed chemical kinetics models describing diesel oil fuel's oxidation behaviour are currently not available; contemporary modelling approaches are focused on simulating surrogate fuels that are considered thermochemically "equivalent" to diesel oil fuel $[2,36,37]$. In the present study, $n$-heptane is used as a surrogate fuel for diesel oil fuel; this assumption is considered reasonable [24], especially in the case of autoignition modelling, since n-heptane's cetane number is very close to that of diesel oil [38, 39]. Additionally, it has been shown that both fuels feature a similar heat release rate for both conventional compression ignition ICE and HCCI ICE [40, 41].

There is a broad body of literature focusing on the development of detailed and reduced/skeletal chemical kinetic mechanisms for $n$-heptane combustion phenomena [21, 23, $38,42-45]$. However, the majority of the available reduced kinetic schemes have been developed aiming to describe the high-temperature, high-pressure conditions prevailing in an ICE cylinder; as a result, they are not capable of accurately reproducing the thermochemical characteristics of the NTC region in low-temperature, atmospheric pressure conditions. The authors have previously performed a comparative study of 7 n-heptane oxidation mechanisms (e.g., reduced, skeletal, semidetailed, and detailed), under conditions relevant to a diesel oil SCF reactor operation [24]. Only 2 mechanisms were found to yield relatively accurate results in all 3 modelled cases for which experimental measurements were available for validation; these were the detailed kinetic mechanism of 
Curran et al. [21], consisting of 550 species and 2481 reactions, and the semidetailed mechanism of Tao et al. [38], involving 57 species and 290 reactions. The mechanism of Tao et al. [38] has been used in a previous effort of developing a "tabulated chemistry" tool capable of simulating diesel oil fuel's cool flame oxidation characteristics $[34,46]$; in the current study, aiming to extend the applicability of the developed tool to higher temperatures, beyond autoignition, the more detailed kinetic mechanism of Curran et al. [21] is utilized. The latter mechanism is capable of thoroughly describing the cool flame regime, by utilizing 25 reaction classes of the characteristic species formed under such conditions (alkylperoxy, hydroperoxy-alkyl and hydroperoxy-alkyl-peroxy radicals, cyclic ethers, carbonyl species, ketohydroperoxydes, and so on). The mechanism has been extensively validated under a variety of reactor types (e.g., plug flow reactor, jet-stirred reactors, shock tubes, and rapid compression machines) [21, 27] and operational conditions (e.g., low-temperature cool flames and high pressure ignition) [21, 27, 28]. Additional validation relevant to the present work has been already shown in [24], while the mechanism has been also shown to be capable of accurately describing the most recent relevant experimental data [27].

Aiming to decrease the high computational cost associated with the solution of the resulting stiff system of nonlinear differential equations, when a chemical kinetics mechanism is implemented in multiphase CFD codes, a broad range of methodologies has been proposed $[15,19]$. The most commonly used methodology is the "reduction" of the detailed chemical kinetics scheme, aiming to significantly decrease the number of the required chemical species and chemical reactions. However, it has been shown that the complex nature of low-temperature oxidation reactions cannot be accurately described by reduced kinetics mechanisms, for example, [24]. Thus, an alternative low-computational cost methodology is used in the current study; the "tabulated chemistry" approach allows the use of detailed chemical kinetics mechanisms, thus being able to effectively retain the essential information regarding the cool flame oxidation phenomena occurring in the low- and intermediate-temperature regimes. In this case, the time-consuming chemistry numerical calculations are $a$ priori performed off-line and the respective results are stored in a multidimensional database ("look-up table"). During the on-line CFD simulations, the tabulated chemical information is accessed by means of a low computational cost retrieval algorithm (e.g., a multilinear interpolation or multivariable correlations).

In order to generate the look-up table data matrix, a large number of chemical kinetic simulations were performed using the perfectly stirred reactor (PSR) assumption. Since low-temperature oxidative phenomena are considered to be kinetically-controlled [14, 46, 47], the PSR approach is considered to be a valid assumption. In this case, each computational cell of the CFD simulations is considered to be an "infinitely fast mixing" PSR exhibiting spatially uniform temperature and mixture composition [48]; turbulence timescale variations are indirectly accounted for through the property transport calculations, whereas the completely homogeneous mixture is exclusively affected by chemical kinetics. A known limitation of the utilized PSR assumption is the need to estimate the mean residence time in each computational (CFD) cell. When each numerical grid cell is assumed to be an independent "equivalent PSR", local velocities and numerical grid length scales can be used to determine the respective residence time; in this case, the obtained results theoretically depend on the selected grid size. However, a range of grid independence studies in a variety of SCF reactors and operational conditions have revealed that the obtained results are not significantly affected by the size of the computational grid, since cool flame heat release rate predictions are monotonously increasing with increasing residence time $[24,34]$.

All computations were performed in an open, adiabatic, PSR environment, featuring unit volume, where the inlet temperature and mixture stoichiometry as well as the reactor's residence time are explicitly specified (independent parameters). The mass balance, species conservation, and energy equations are solved using the CHEMKIN software [49]. Particular attention has been paid in providing the initial guess of the outlet temperature and in determining the convergence criteria, since solution of the respective equations using large detailed kinetic mechanisms is mathematically stiff.

2.1. Selection of Parameters. It is well documented that the main operational parameters affecting cool flame behaviour are pressure, temperature, and fuel concentration $[13,15,17]$. Since the current study focuses on atmospheric pressure conditions, pressure was not varied. As a result, the 3 operational parameters selected were the inlet temperature $\left(T_{\text {in }}\right)$, the inlet fuel concentration (expressed via the respective fuel mass fraction, $Y_{\text {fuel }}$, defined as the ratio of the fuel mass over the total inlet mixture mass), and the total residence time in the PSR $\left(t_{\text {res }}\right)$. The variation range for each parameter was decided using relevant information obtained both in experimental $[50,51]$ and simulation $[25,30]$ studies; the limiting values were selected to extend beyond the typical values expected in the corresponding technical devices. Inlet temperature values extended from $550 \mathrm{~K}$ to $1000 \mathrm{~K}$, thus covering the entire low- and intermediate-temperature oxidation regions, as well as autoignition phenomena. Fuel mass fraction values extended from 0.005 to 0.5 ; these values correspond to an equivalence ratio ranging from very lean mixtures $(\lambda=13)$ to very rich mixtures $(\lambda=0.07)$. Here, the lambda factor, $\lambda$, is defined as the ratio of the actual air-to-fuel ratio over the stoichiometric one. The majority of the selected values are distributed near stoichiometric conditions. Finally, residence time values spanned 3 orders of magnitude, ranging from $0.5 \mathrm{~ms}$ to $0.5 \mathrm{~s}$. All in all, 34848 different chemical kinetics simulations were performed, corresponding to all triplet combinations of the respective values (Table 1).

For each triplet $\left(T_{\text {in }}, Y_{\text {fuel }}, t_{\text {res }}\right)$ combination, values of the obtained simulation results were stored in the data matrix. The stored values regarded thermal quantities, such as total heat release per unit volume, $\mathrm{HR}\left(\mathrm{kJ} / \mathrm{m}^{3}\right)$ or outlet temperature, $T_{\text {out }}(\mathrm{K})$, and kinetic quantities, for example, species rate of production or destruction, $\omega_{i}\left(\mathrm{~kg} / \mathrm{m}^{3} \mathrm{~s}\right)$, or outlet species mole fraction, $X_{i}$. The size of the obtained database can be 
TABLE 1: Variation range of selected independent parameters.

\begin{tabular}{lcccc}
\hline Parameter & Symbol & Units & Range & $\begin{array}{c}\text { Number } \\
\text { of nodes }\end{array}$ \\
\hline Inlet temperature & $T_{\text {in }}$ & $\mathrm{K}$ & $550-1000$ & 33 \\
Fuel mass fraction & $Y_{\text {fuel }}$ & $\mathrm{kg}_{\text {fuel }} / \mathrm{kg}_{\text {mixture }}$ & $0.005-0.5$ & 33 \\
Residence time & $t_{\text {res }}$ & $\mathrm{s}$ & $0.0005-0.5$ & 32 \\
\hline
\end{tabular}

customized, by excluding unneeded information, depending on the required accuracy of the performed CFD simulations. For instance, if only a rather simplistic approximation of the thermochemical behaviour of the cool flame region is needed, the size of the database may be significantly reduced so as to contain only simulation results regarding heat release rate, which is introduced to the CFD code as a local heat "source" term, and fuel consumption rate, which corresponds to a fuel concentration "sink" term in the CFD code. Despite the significant simplifying assumptions, this methodology is known to yield adequately accurate predictions in the case of multiphase CFD simulations of atmospheric pressure SCF diesel oil evaporation devices, as demonstrated in relevant validation studies, for example, $[24,34]$.

\section{Results and Discussion}

The obtained numerical results allow a systematic investigation of the effect of the examined independent parameters on the thermochemical behaviour of $n$-heptane, both in the low-temperature oxidation and autoignition regimes. A selection of characteristic results is presented in the following sections, aiming to highlight the most prominent observations. Furthermore, in order to obtain a more indepth understanding of the thermochemical behaviour of the n-heptane oxidation, extensive reaction path and sensitivity analyses have been performed aiming to delineate the major chemical pathways controlling the heat release and species production/consumption processes occurring during n-heptane oxidation. Reaction path (or rate-of-production) and sensitivity analyses constitute major tools in understanding reacting flows. Rate-of-production analysis determines the contribution of each reaction to the net production or destruction rate of a species and provides a static picture of the entire reaction network. Species formation and destruction paths are revealed through such an analysis. On the other hand, sensitivity analysis gives information regarding the influence of a specific reaction to a certain species, thus providing a more dynamic understanding of chemical interactions. The sensitivity coefficient is defined as $\partial F / \partial \alpha$, where $F$ is a target value (e.g., temperature, heat release rate, or species concentration) and $\alpha$ is the preexponential factor in the Arrhenius rate constant expression. The nomenclature of species naming as well as reaction numbering of the considered detailed kinetic mechanism are identical to the original publication of Curran et al. [21].

3.1. Predictions of Heat Release. A typical snapshot of the formulated database is presented in Figure 1, where predictions of heat release per unit volume (HR) are depicted as a

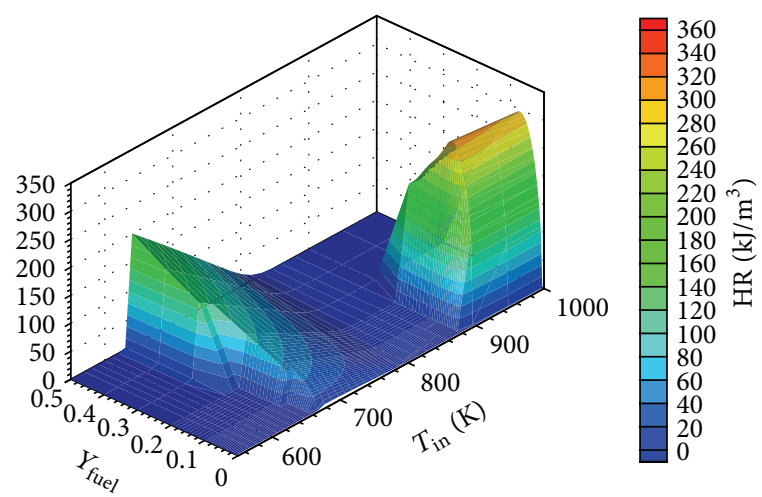

Figure 1: Predictions of heat release per unit volume as a function of inlet temperature and fuel concentration $\left(t_{\text {res }}=5 \mathrm{~ms}\right)$.

function of both inlet temperature and fuel mass fraction, for a characteristic residence time of $5 \mathrm{~ms}$. Two main chemical activity regimes can be identified. The conventional "ignition" region emerges at temperatures higher than $880 \mathrm{~K}$; the corresponding exothermal activity practically ceases at extremely fuel-rich conditions $\left(Y_{\text {fuel }}>0.3\right)$. This "quenching" behaviour is attributed to the significant reduction of essential radical species concentrations observed at high temperatures $\left(T_{\text {in }}>\right.$ $900 \mathrm{~K}$ ) and fuel-rich mixtures; in fact, predictions of $\mathrm{H}$ and $\mathrm{OH}$ radicals concentrations are decreased by almost 5 orders of magnitude, when the inlet fuel concentration is quintupled, from a near stoichiometric value $\left(Y_{\text {fuel }}=0.06\right.$, $\lambda=1.04)$ to significantly fuel-rich conditions $\left(Y_{\text {fuel }}=0.3\right.$, $\lambda=0.16)$. On the other hand, heat release due to cool flame reactions is intensified with increasing fuel concentration; the "cool flame" regime is mainly observed at the lowand intermediate-temperature oxidation regions, extending approximately between $620 \mathrm{~K}$ and $800 \mathrm{~K}$. Maximum heat release values in the cool flame regime are found to emerge at the highest fuel concentration levels considered in this study $\left(Y_{\text {fuel }}=0.5\right)$ and correspond to approximately $70 \%$ of the maximum heat release values observed at the ignition regime, observed near stoichiometric $\left(Y_{\text {fuel,st }}=0.062\right)$ conditions.

By further investigating the information stored in the formulated chemical database, taking into consideration similar multiparameter plots corresponding to all the investigated residence time values, certain observations are found to be universally valid. In general, the "cool flame" regime broadens with increasing fuel concentration and the temperature where the respective peak heat release value is observed decreases with increasing fuel concentration. On the other hand, the ignition regime appears to be rather insensitive to the variation of the main operating parameters; peak values correspond invariably to approximately stoichiometric mixture conditions, whereas a "pre-ignition" regime featuring moderate heat release values is formed at richer mixtures.

In Figure 2, predictions of heat release per unit volume are depicted as a function of inlet temperature, for 5 characteristic fuel concentration levels, at a constant residence time $\left(t_{\text {res }}=30 \mathrm{~ms}\right)$. It is evident that cool flame exothermic activity is enhanced with increasing fuel concentration; such behaviour is corroborated by similar findings in relevant 


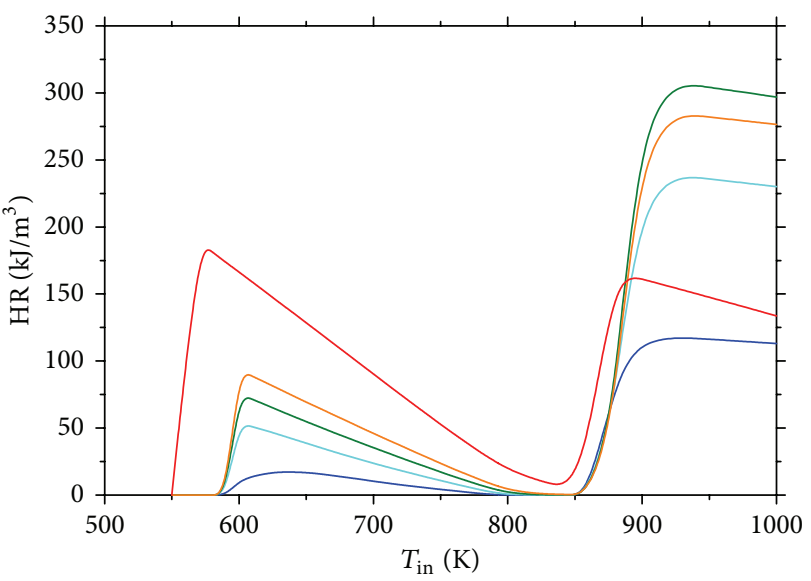

$$
\begin{array}{ll}
Y_{\text {fuel }}(\lambda) & \\
-0.01(6.56) & -0.10(0.60) \\
-0.03(2.14) & -0.30(0.16)
\end{array}
$$

FIGURE 2: Predictions of heat release per unit volume as a function of inlet temperature for 5 characteristic values of fuel concentration $\left(t_{\text {res }}=30 \mathrm{~ms}\right)$.

experimental studies [17, 29]. The "peak" of the cool flame heat release predictions becomes more pronounced at fuelrich conditions, resulting in steeper curve slopes at the NTC region; the characteristic inlet temperature that corresponds to the maximum heat release value decreases with increasing fuel concentration. However, the temperature region where cool flame activity is observed remains practically constant $(580 \mathrm{~K}-800 \mathrm{~K})$, with the sole exception of extremely fuel-rich conditions $\left(Y_{\text {fuel }}=0.3\right.$ ), where the respective temperature limits are broadened $(550 \mathrm{~K}-840 \mathrm{~K})$. On the other hand, the temperature region where high-temperature oxidation is observed remains practically constant $\left(T_{\text {in }}>850 \mathrm{~K}\right)$ for all the considered fuel concentration values. Peak heat release predictions at the ignition regime are observed for stoichiometric conditions; the respective values decrease when fuel concentration is either increased (fuel-rich region) or decreased (fuel-lean region).

The variation of heat release per unit volume predictions as a function of inlet temperature, for 5 characteristic residence time values, at a constant fuel concentration level $\left(Y_{\mathrm{fu}}=\right.$ 0.06 ), corresponding to nearly stoichiometric conditions, is depicted in Figure 3. As expected, longer residence times result in higher heat release values. The effect of residence time on the cool flame activity regime is prominent; when the residence time is increased, the cool flame temperature region is significantly extended, whereas the maximum heat release value is "shifted" towards lower temperatures. A kinetic interpretation of such behaviour is that given sufficient time, the continuous production of intermediate species (e.g., aldehydes) results in the increased production of hydroperoxyalkyl radicals $(\mathrm{QOOH})$ and hydrogen peroxide $\left(\mathrm{H}_{2} \mathrm{O}_{2}\right)$, which favour chain-propagation reactions, thus leading to enhanced cool flame exothermal activity [52]. The respective effects on the ignition regime are less prominent; increasing the residence time results in a slight decrease of the lower
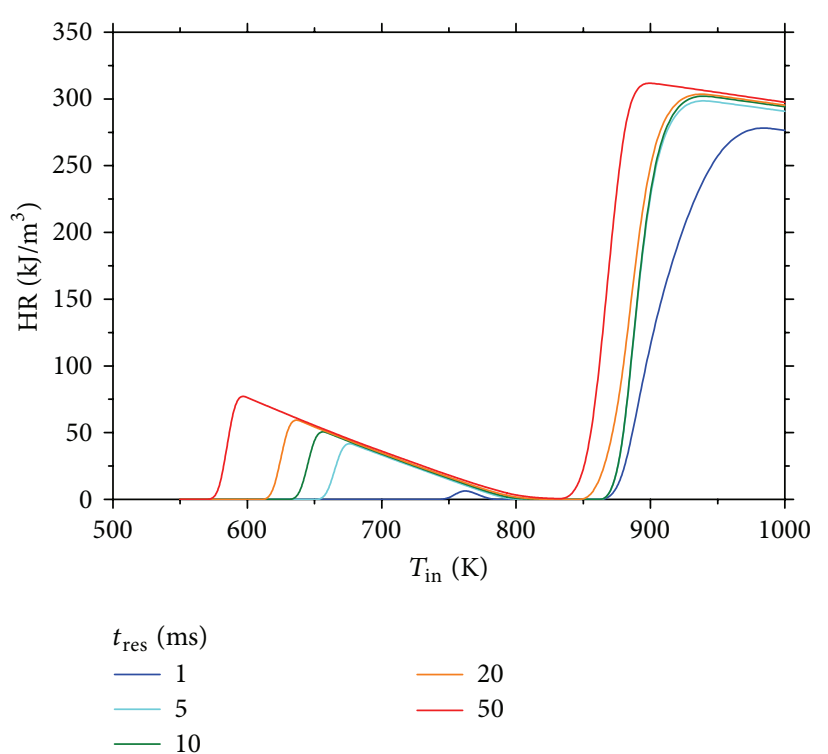

FIgURE 3: Predictions of heat release per unit volume as a function of inlet temperature for 5 characteristic values of residence time $\left(Y_{\text {fuel }}=\right.$ $0.06)$.

temperature limit of the respective region, as well as a slight increase of the observed maximum value.

Predictions of heat release per unit volume as a function of residence time, for 5 characteristic fuel concentration levels, at a constant inlet temperature $\left(T_{\text {in }}=740 \mathrm{~K}\right)$, corresponding to the main cool flame activity region, are depicted in Figure 4. The cool flame exothermal activity is enhanced with increasing residence time; at residence time values higher than approximately $3 \mathrm{~ms}$, the predicted heat release values are practically constant. A further increase is observed at residence times higher than $0.05 \mathrm{~s}$, only under extremely fuel-rich conditions $\left(Y_{\text {fuel }}=0.3\right)$.

3.2. Predictions of Species Production and Consumption. Information regarding the exact mixture composition is very important for a large variety of technical applications (e.g., high temperature reforming for fuel cell applications, HCCI ICE). Figure 5 presents predictions of the fuel consumption rate per unit volume as a function of both inlet temperature and fuel concentration, for a constant residence time value $\left(t_{\text {res }}=5 \mathrm{~ms}\right)$. Fuel consumption rates in the cool flame regime are almost twice the respective values observed in the ignition regime. Interestingly enough, modest fuel consumption rates are observed in the fuel-rich region at higher temperatures, despite the fact that there is no significant exothermic heat release observed in the same region (compare with Figure 1).

In order to further investigate the thermochemical behaviour of the fuel-rich high-temperature oxidation regime, a reaction path analysis has been performed. In the fuel-rich and high-temperature case $\left(Y_{\text {fuel }}=0.3\right.$, $\left.T_{\text {in }}=950 \mathrm{~K}\right)$, n-heptane is equally consumed through the competing endothermic $\mathrm{H}$-abstraction reactions with the $\mathrm{HO}_{2}$ radical and the exothermic reactions with the $\mathrm{OH}$ radical (each type of reaction accounts for almost $40 \%$ of the total fuel consumption rate). Therefore, although the 

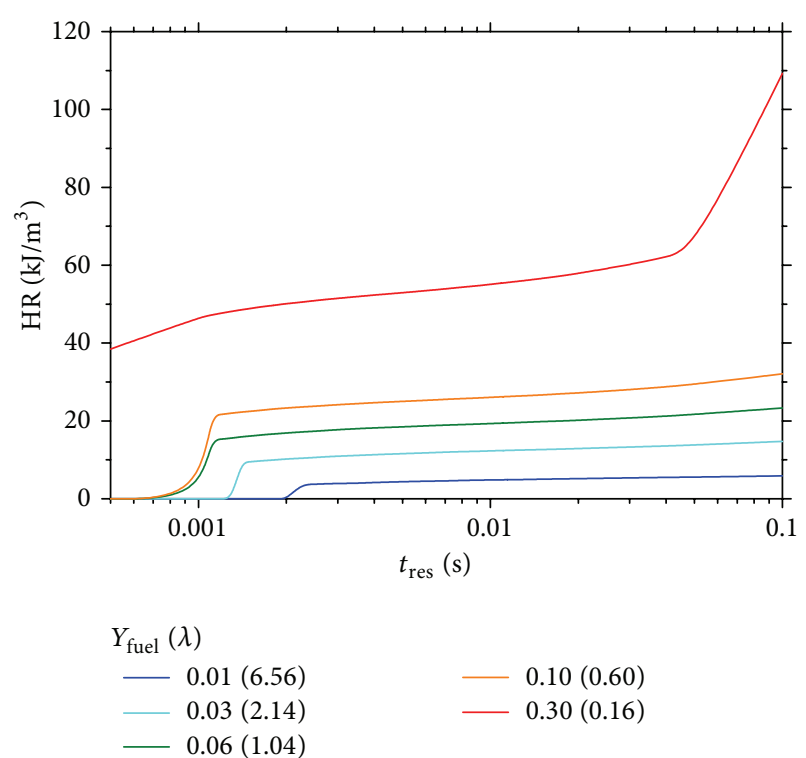

FIGURE 4: Predictions of heat release per unit volume as a function of residence time for 5 characteristic values of fuel concentration $\left(T_{\text {in }}\right.$ $=740 \mathrm{~K})$.

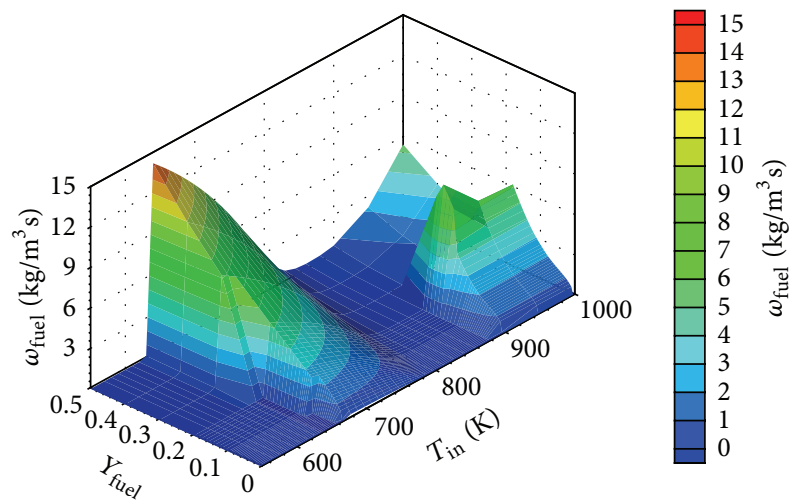

FIGURE 5: Predictions of fuel consumption rate per unit volume as a function of inlet temperature and fuel concentration $\left(t_{\text {res }}=5 \mathrm{~ms}\right)$.

fuel molecule is being consumed, the net heat production from gas-phase reactions is slightly negative. Decreasing the inlet fuel concentration $\left(Y_{\text {fuel }}=0.2, T_{\text {in }}=950 \mathrm{~K}\right)$ and moving towards stoichiometric conditions, the $\mathrm{H}$-abstraction reactions as well as fuel decomposition reactions to $\mathrm{C}_{6}+$ $\mathrm{C}_{1}$ (e.g., $\mathrm{n}-\mathrm{C}_{7} \mathrm{H}_{16} \Leftrightarrow \mathrm{C}_{6} \mathrm{H}_{13}-1+\mathrm{CH}_{3}$ ), $\mathrm{C}_{5}+\mathrm{C}_{2}$ (e.g., n- $\mathrm{C}_{7} \mathrm{H}_{16}<=\mathrm{C}_{5} \mathrm{H}_{11}-1+\mathrm{C}_{2} \mathrm{H}_{5}$ ), and $\mathrm{C}_{4}+\mathrm{C}_{3}$ species (e.g., n$\mathrm{C}_{7} \mathrm{H}_{16}<=>\mathrm{pC}_{4} \mathrm{H}_{9}+\mathrm{n}-\mathrm{C}_{3} \mathrm{H}_{7}$ ) become dominant. Due to the high outlet temperature $\left(T_{\text {out }}>2000 \mathrm{~K}\right)$, the aforementioned fuel decomposition reactions serve as initiation steps, despite their high activation energy. Subsequently, the formed $\mathrm{C}_{4}$ and $\mathrm{C}_{5}$ species, promptly further decompose to $\mathrm{C}_{2}$ and $\mathrm{C}_{3}$ species, thus initiating the heat release producing chain, from $\mathrm{C}_{2} \mathrm{H}_{4}$ down to $\mathrm{CO}$; therefore, significant exothermal activity emerges near the stoichiometric mixture conditions (compare with Figure 1).

In Figure 6, predictions of the fuel consumption rate per unit volume are depicted as a function of inlet temperature,
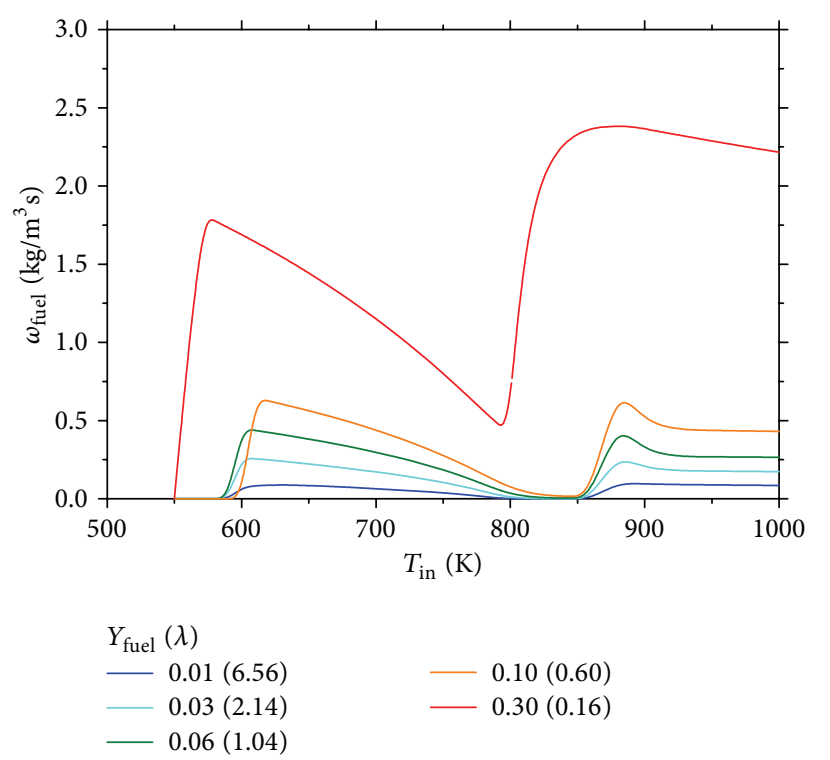

FIgURE 6: Predictions of fuel consumption rate per unit volume as a function of inlet temperature for 5 characteristic values of fuel concentration $\left(t_{\text {res }}=30 \mathrm{~ms}\right)$.
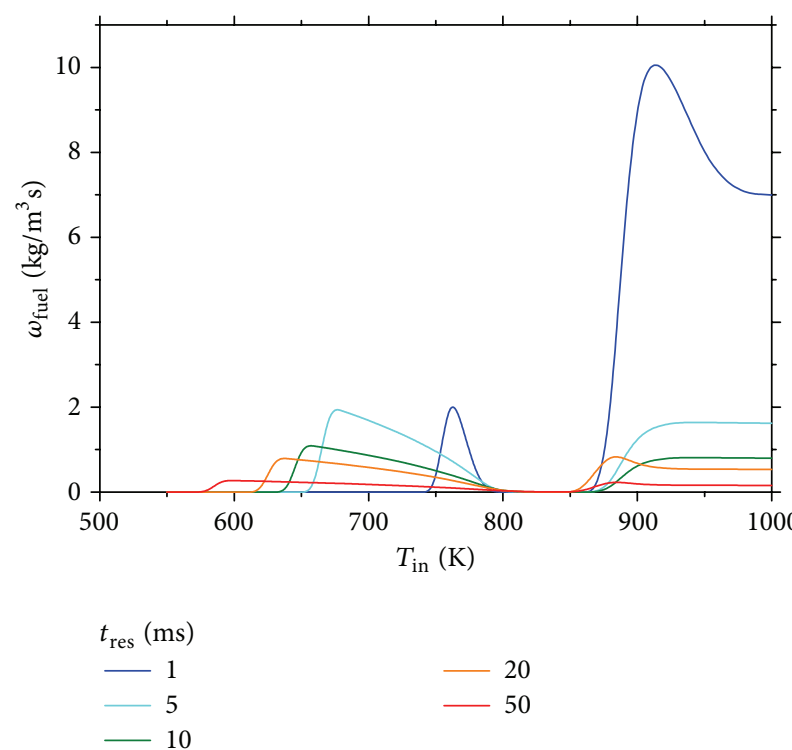

FIGURE 7: Predictions of fuel consumption rate per unit volume as a function of inlet temperature for 5 characteristic values of residence time $\left(Y_{\text {fuel }}=0.06\right)$.

for 5 characteristic fuel concentration levels, at a constant residence time $\left(t_{\text {res }}=30 \mathrm{~ms}\right)$. The emerging "cool flame" and "ignition" regimes are once more identified; as expected, increasing initial fuel concentration results in higher fuel consumption rates. The general form of the obtained curves is similar to that of the respective curves corresponding to heat release predictions (c.f. Figure 2); however, as mentioned before, the significant fuel consumption rates observed in the ignition regime under fuel-rich conditions are not accompanied by respective important exothermic heat release. 

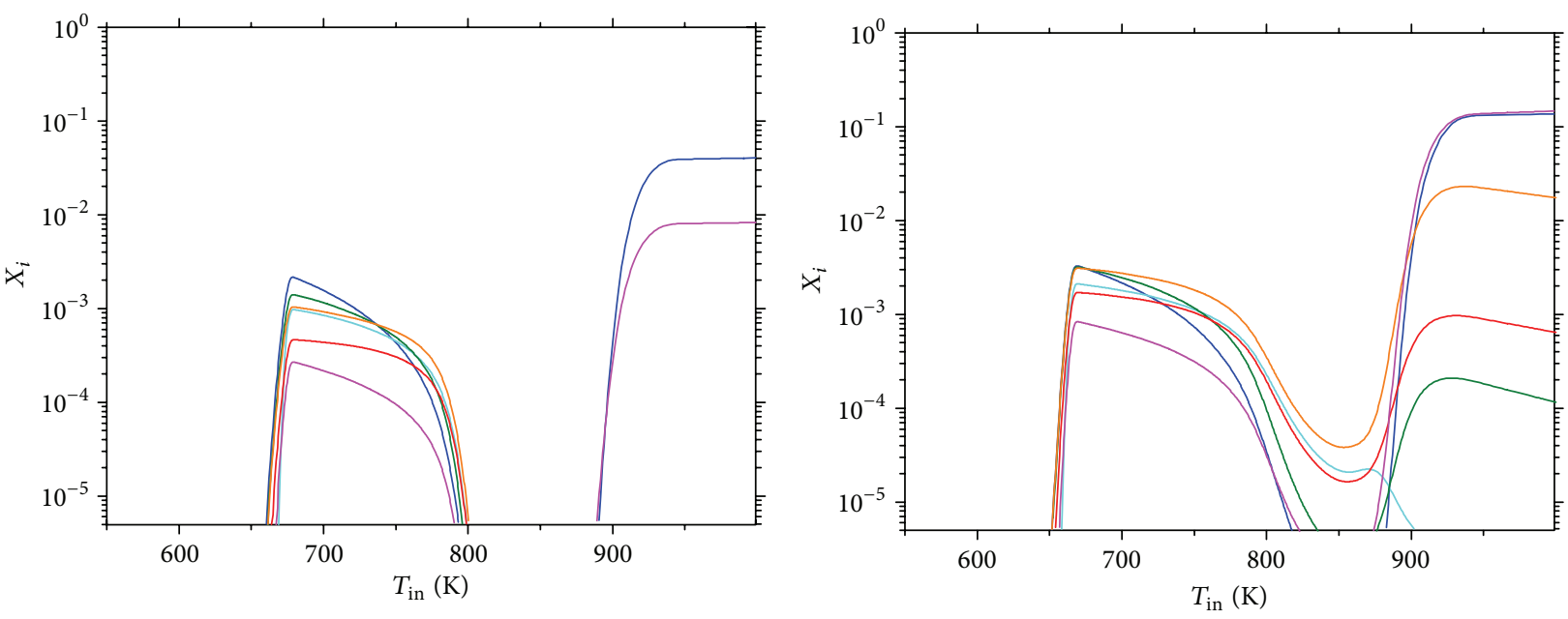

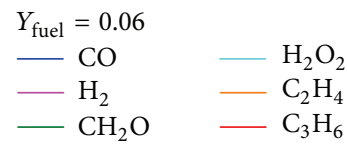

(a)

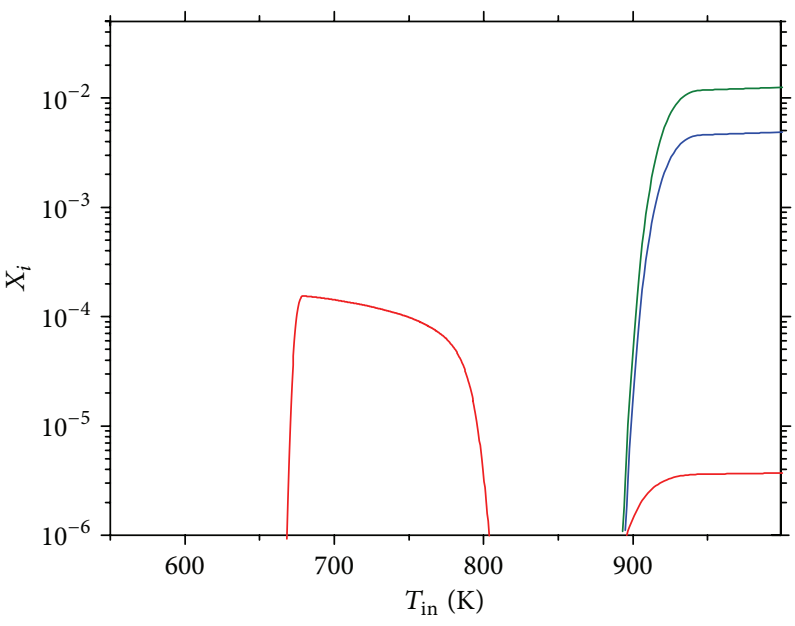

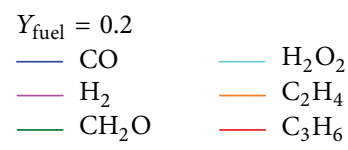

(b)

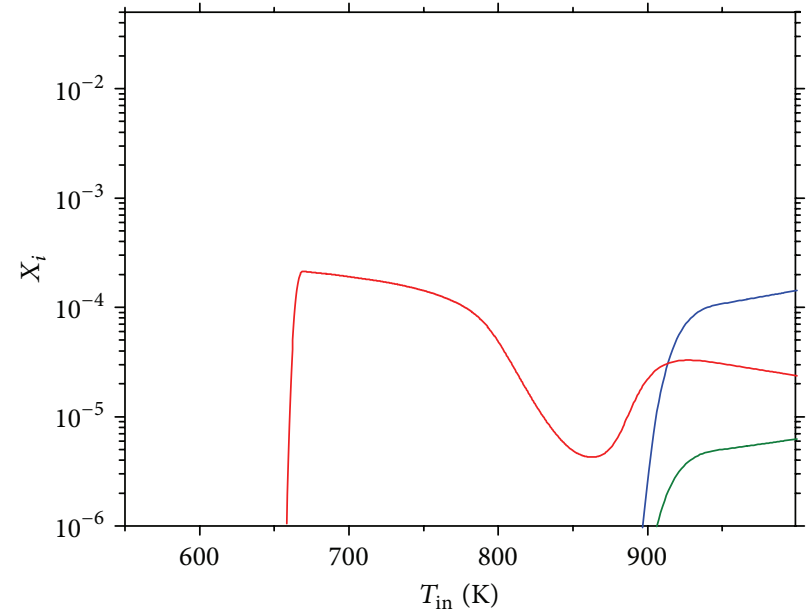

$\begin{array}{ll}Y_{\text {fuel }}=0.2 & \\ -\mathrm{H} & -\mathrm{OH} \\ \mathrm{HCO} & -\mathrm{HO}_{2}\end{array}$

(d)

d)

(c)

FIGURE 8: Predictions of species mole fraction as a function of inlet temperature for 2 characteristic inlet fuel concentration values $\left(t_{\text {res }}=5\right.$ ms $)$.

The variation of the fuel mass consumption rate per unit volume as a function of inlet temperature, for 5 characteristic residence time values, at a constant (near stoichiometric) fuel concentration $\left(Y_{\text {fuel }}=0.06\right)$, is depicted in Figure 7. As expected, increasing the residence time results in decreasing fuel consumption rate values, since the latter correspond, essentially, to time gradients; this is evident in the ignition region, when the residence time is sufficiently small $\left(t_{\text {res }}=\right.$ $1 \mathrm{~ms}$ ). Similar to the respective heat release predictions (c.f. Figure 3), the effect of residence time variation on the cool flame activity regime is prominent; when the residence time is increased, the cool flame regime is significantly extended, whereas the maximum fuel consumption rate values are "shifted" towards lower temperatures. Once more, the moderate fuel consumption rates observed in the ignition region result in significantly higher exothermic heat release, compared to the respective values of the cool flame regime (c.f. Figure 3).

In order to further investigate the effect of the different kinetic paths prevailing in the cool flame and ignition regimes, predictions of several crucial major stable and radical species are presented in Figure 8 . The depicted mole fraction predictions are presented as a function of inlet temperature $\left(t_{\text {res }}=5 \mathrm{~ms}\right)$, for two fuel concentration 

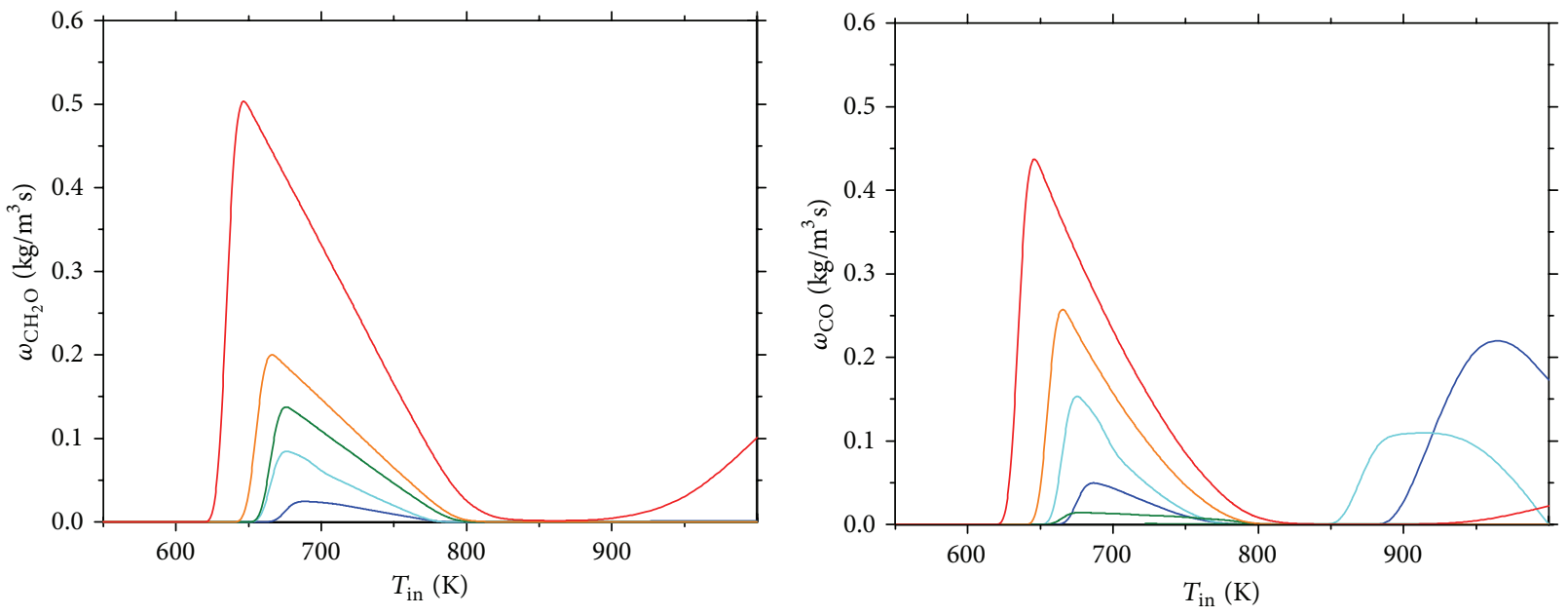

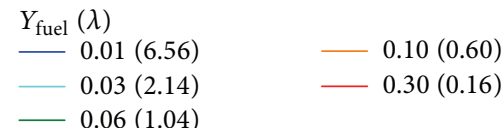

(a)

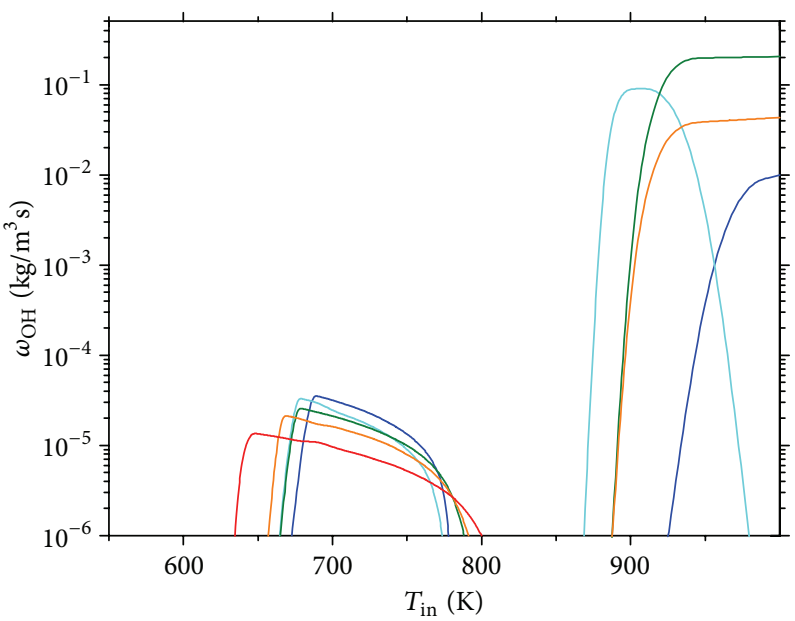

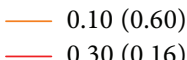

$0.30(0.16)$

(c)

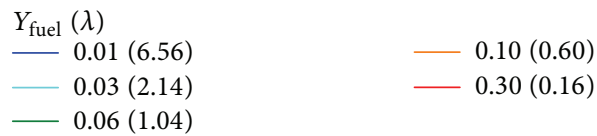

(b)

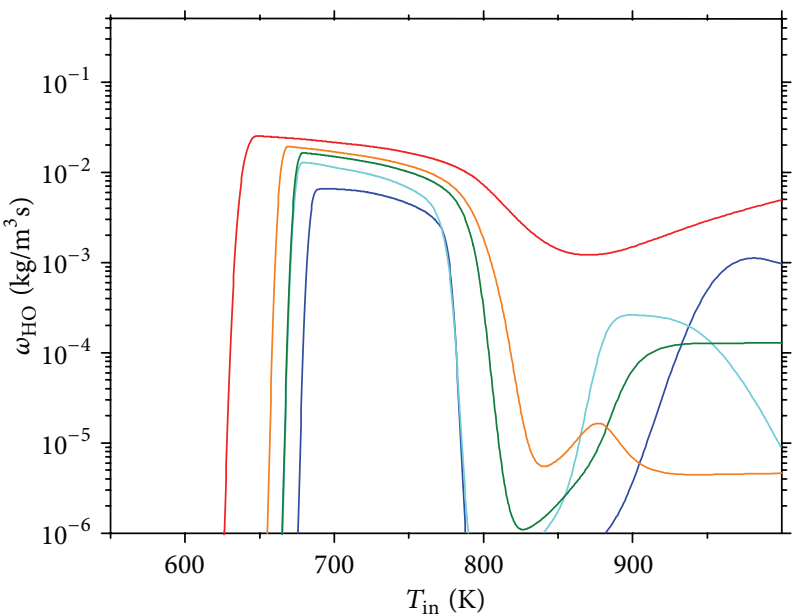

$Y_{\text {fuel }}(\lambda)$
$-0.01(6.56)$
$-0.03(2.14)$
$-0.06(1.04)$
$-0.30(0.16)$

(d)

Figure 9: Predictions of $\mathrm{CH}_{2} \mathrm{O}, \mathrm{CO}, \mathrm{OH}$, and $\mathrm{HO}_{2}$ production rates per unit volume as a function of inlet temperature for 5 characteristic values of fuel concentration $\left(t_{\text {res }}=5 \mathrm{~ms}\right)$.

levels, one corresponding to approximately stoichiometric conditions $\left(Y_{\text {fuel }}=0.06\right)$ and the other referring to fuelrich conditions $\left(Y_{\text {fuel }}=0.2\right)$. It is evident that species concentration levels are significantly different in the lowand high-temperature oxidation regimes. In terms of radical species, the cool flame region is characterized by significant $\mathrm{OH}$ and $\mathrm{H}_{2} \mathrm{O}_{2}$ formation, whereas the ignition region is dominated by $\mathrm{H}$ and $\mathrm{OH}$ production. Also, while the major stable species emerging in the ignition region are $\mathrm{CO}$ and $\mathrm{H}_{2}$, the cool flame regime is characterized by significant production of a large variety of species, such as $\mathrm{CH}_{2} \mathrm{O}, \mathrm{H}_{2} \mathrm{O}_{2}$, $\mathrm{C}_{2} \mathrm{H}_{4}, \mathrm{C}_{3} \mathrm{H}_{6}$, and so forth. The above findings are also in agreement with recent experimental evidence [28].

The prevailing kinetic mechanisms governing the oxidative reactions of $\mathrm{n}$-heptane are continuously changing depending on the temperature of the mixture; this remark is clearly elucidated by comparing predictions of the production rate per unit volume for various important stable $\left(\mathrm{CH}_{2} \mathrm{O}\right.$, $\mathrm{CO})$ and radical $\left(\mathrm{HO}_{2}, \mathrm{OH}\right)$ species, which are depicted in Figure 9. The selected species are indicative of the difference 


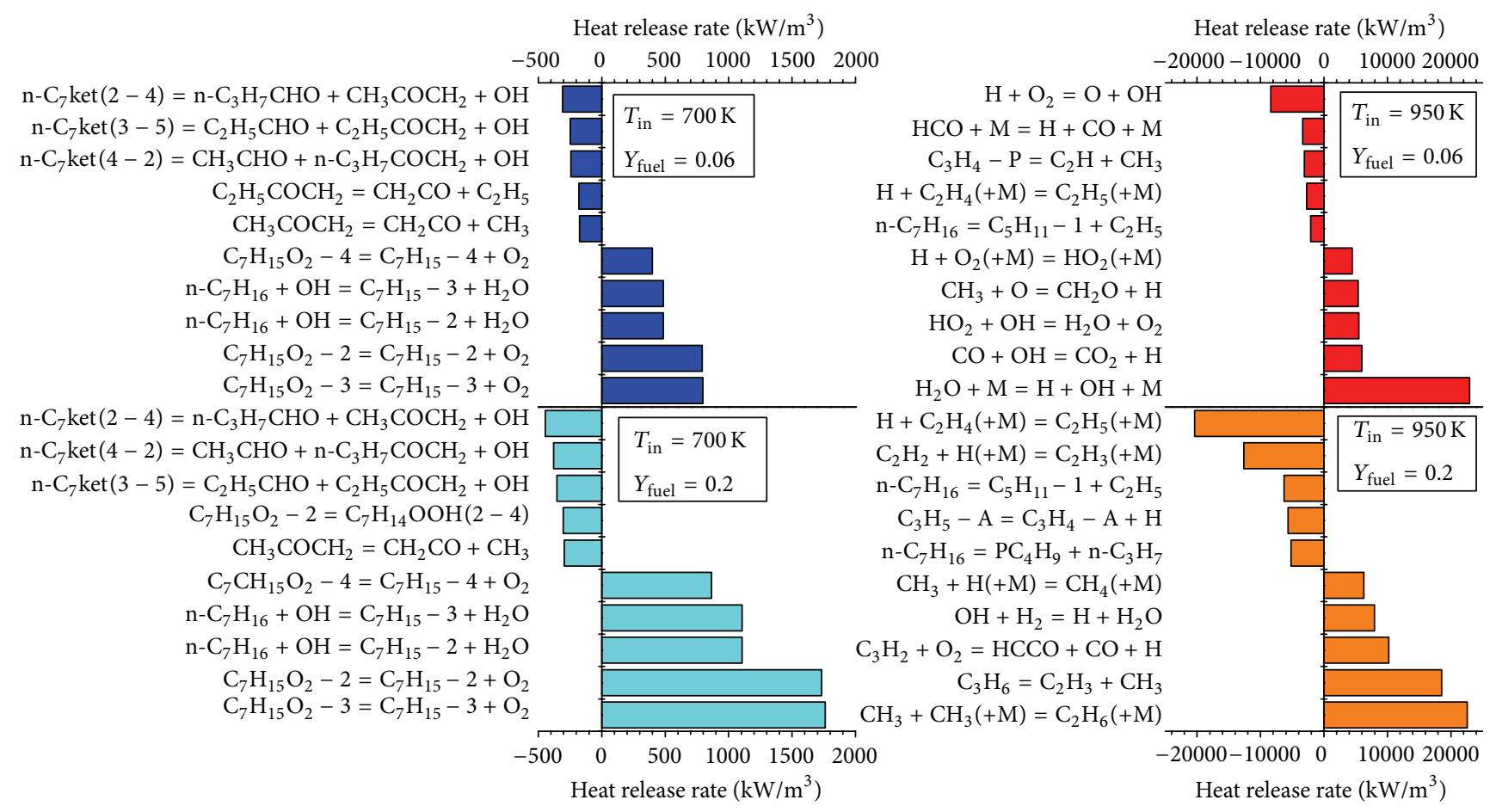

FIGURE 10: Predictions of heat release rate per unit volume for the reactions exhibiting maximum absolute endothermic and exothermic values $\left(t_{\text {res }}=5 \mathrm{~ms}\right)$.

in reactivity between the low- and high-temperature oxidation regimes. For instance, increasing inlet fuel concentrations results in significant production of formaldehyde in the cool flame regime; in the ignition regime, the produced quantities are rather insignificant. On the other hand, CO production rates are significant in both the cool flame and ignition regimes. Similar observations are obtained regarding the important radical species. $\mathrm{HO}_{2}$ production is significant only in the cool flame regime (increasing with increasing fuel concentration), whereas $\mathrm{OH}$ is essentially produced mainly under high-temperature oxidation conditions; in the latter case, maximum values are observed near the stoichiometric conditions.

3.3. Sensitivity Analysis. As it has been already demonstrated in similar studies, for example, $[45,53]$, sensitivity analysis of the utilized kinetic mechanism may reveal the kinetic paths prevailing under different operating conditions. Figure 10 presents the elementary reactions exhibiting maximum absolute endothermic and exothermic heat release values, for a near stoichiometric $\left(Y_{\text {fuel }}=0.06\right)$ and a rich $\left(Y_{\text {fuel }}=0.2\right) n$ heptane/air mixture, at two different inlet temperatures, one indicative of the cool flame regime $\left(T_{\text {in }}=700 \mathrm{~K}\right)$ and the other corresponding to the ignition regime $\left(T_{\text {in }}=950 \mathrm{~K}\right)$. Clearly, mixture stoichiometry has a less prominent effect on the system's behavior as compared to that imposed by the inlet temperature. In the cool flame regime, decomposition reactions of the ketohydroperoxides ( $n-C_{7}$ ket) species are the major endothermic chemical steps. The thermochemical behaviour is also controlled by the competition between isomerisation (endothermic) and decomposition (exothermic) alkylperoxy reactions. Naturally, fuel depletion reactions through $\mathrm{OH}$ radical attack and $\mathrm{HO}_{2}$ production processes largely contribute to the overall exothermicity. On the other hand, heat release processes at higher temperatures, where ignition occurs, are largely determined by the $\mathrm{H}_{2} / \mathrm{O}_{2}$ system. Note that in the case of the fuel-rich mixture $\left(Y_{\text {fuel }}=0.2\right)$, ketyl radical (HCCO) chemistry becomes important as well as reactions of $\mathrm{C}_{3}$ species (see also computed $\mathrm{C}_{3} \mathrm{H}_{6}$ levels in Figure 8).

The calculated outlet temperature sensitivity coefficients for elementary reactions that exhibit the largest absolute values are shown in Figure 11, for two inlet temperature values, $T_{\text {in }}=700 \mathrm{~K}$ (cool flame regime) and $T_{\text {in }}=950 \mathrm{~K}$ (ignition regime), and two residence time values $\left(t_{\text {res }}=5\right.$ and $30 \mathrm{~ms})$, at a constant inlet fuel concentration $\left(Y_{\text {fuel }}=0.06\right)$. Positive values of the sensitivity coefficient indicate that an increase in the particular reaction rate constant results in a corresponding increase in the outlet temperature value.

In the cool flame regime, residence time has a negligible impact on the temperature sensitivity; however, it does play a role in the high-temperature oxidation regime. It is evident that the elementary reactions affecting the heat release are significantly different in the two main oxidation regimes. An interesting observation is that, in the cool flame regime $\left(T_{\text {in }}=700 \mathrm{~K}\right)$, the alkylperoxy radical isomerisation reaction class (e.g., $\mathrm{C}_{7} \mathrm{H}_{15} \mathrm{O}_{2} \Leftrightarrow=\mathrm{C}_{7} \mathrm{H}_{14} \mathrm{OOH}$ ) results in both positive and negative sensitivity coefficients. However, it is arguable to suggest that a faster overall isomerization towards hydroperoxy-alkyl species formation would result in increased overall reactivity; see also [21]. The major fuel oxidation paths involving $\mathrm{OH}$ radical attack 


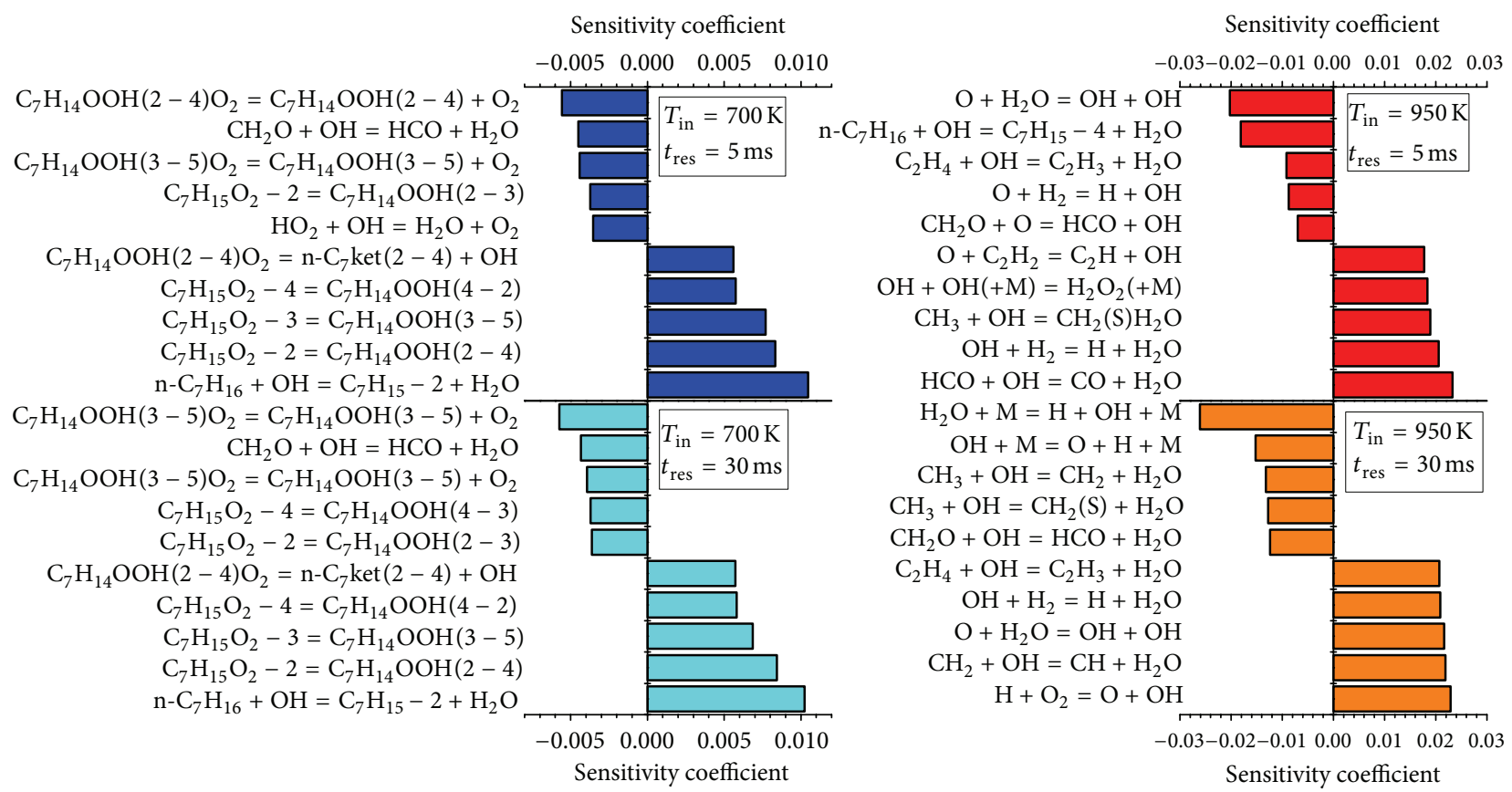

FIGURE 11: Computed outlet temperature sensitivity coefficients for two inlet temperature values, $T_{\text {in }}=700 \mathrm{~K}$ (cool flame regime) and $T_{\text {in }}=$ $950 \mathrm{~K}$ (ignition regime), and two residence time values $\left(t_{\text {res }}=5\right.$ and $\left.30 \mathrm{~ms}\right)$, at a constant inlet fuel concentration $\left(Y_{\text {fuel }}=0.06\right)$.

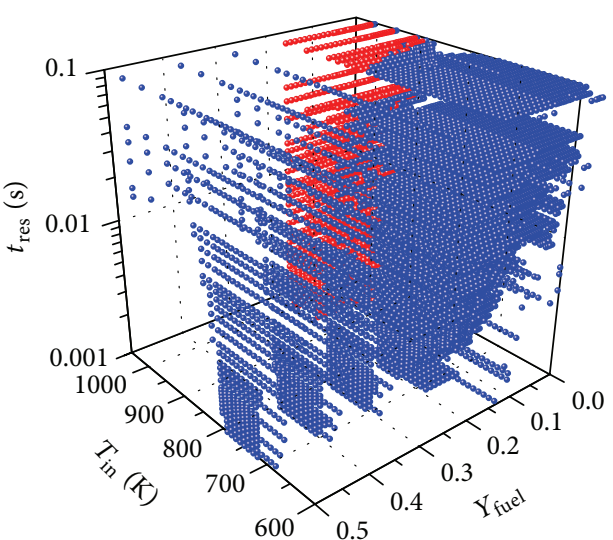

(a)

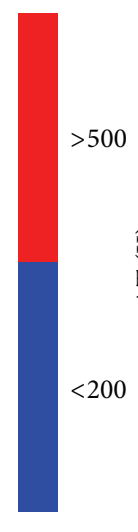

8

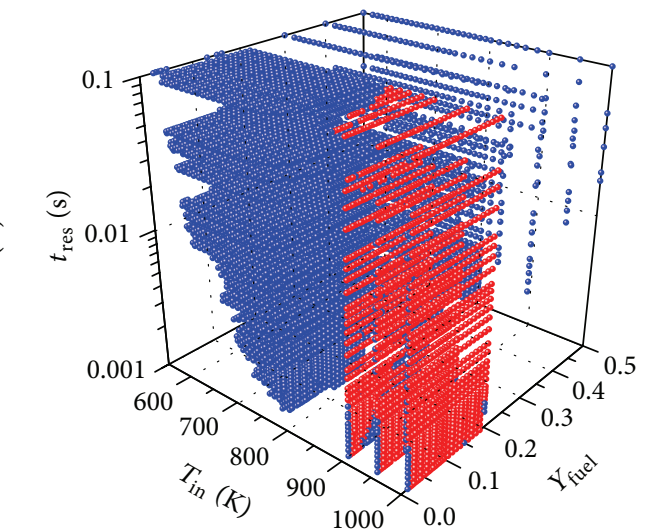

(b)

FIGURE 12: Predictions of PSR temperature increase as a function of inlet temperature, fuel concentration, and residence time.

and ketoxyhydro-peroxide (notated as $\mathrm{n}-\mathrm{C}_{7}$ ket) species production reactions favour temperature rise. On the other hand, $\mathrm{O}_{2} \mathrm{C}_{7} \mathrm{H}_{14} \mathrm{OOH}$ decomposition reactions and the $\mathrm{OH}$ consuming reactions (e.g., $\mathrm{CH}_{2} \mathrm{O}+\mathrm{OH} \Leftrightarrow=\mathrm{HCO}+\mathrm{H}_{2} \mathrm{O}$ and $\mathrm{HO}_{2}+\mathrm{OH}<=>\mathrm{H}_{2} \mathrm{O}+\mathrm{O}_{2}$ ) tend to decrease the observed outlet temperature values. In the case of the high-temperature regime, no fuel specific reactions appear to control ignition. In fact, the system's overall exothermic activity is exclusively controlled by the fate of the available radical pool, which in turn depends on the competition of chain-branching and chain-terminating reactions.
3.4. Thermochemical Behaviour and Tool Validation. The information obtained in the process of developing the tabulated chemistry tool can be also utilized to develop characteristic thermochemical behaviour "maps," which enable the assessment of the expected conditions emerging in technical devices when certain operational parameter values are employed. Such multidimensional maps are essentially similar to 2D "ignition diagrams," describing the thermal behaviour of technical devices operating in the low- to high-temperature oxidation regimes [9, 51]. In Figure 12, an indicative thermochemical behaviour map is depicted; the 


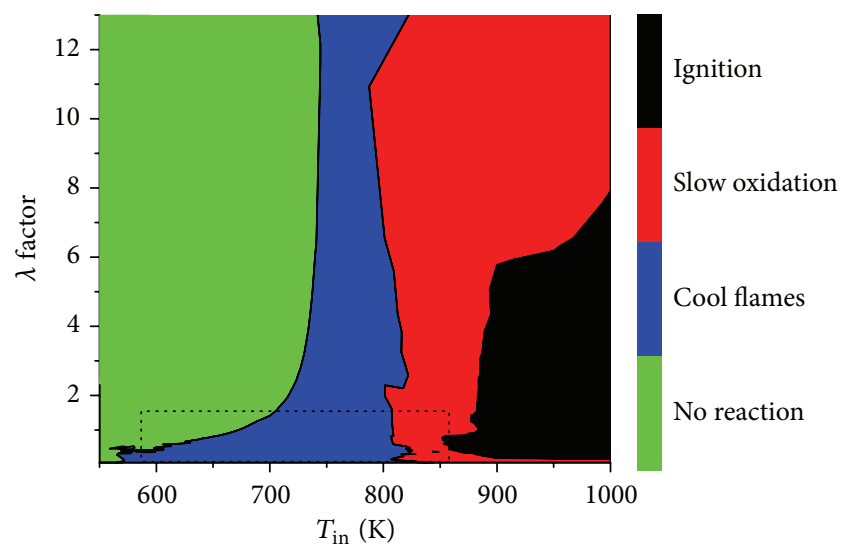

FIGURE 13: Predictions of main reactivity regions as a function of inlet temperature and lambda factors.

main operating regions, that is, cool flame and autoignition, are identified by utilizing the predicted temperature increase, between the reactor's inlet and outlet $\left(\Delta T=T_{\text {out }}-T_{\text {in }}\right)$. Conventionally, a temperature increase lower than $200 \mathrm{~K}$ [45] corresponds to the cool flame regime, whereas a temperature increase higher than $500 \mathrm{~K}$ suggests that autoignition is occurring. Each point depicted in the multidimensional plot corresponds to the predicted temperature increase for each of the 34848 PSR simulations; however, for the sake of clarity, operating conditions resulting in negligible $\Delta T$ (cf. areas of near zero heat release in Figure 1) are not shown.

The multidimensional graph of $T_{\text {in }}, Y_{\text {fuel }}, t_{\text {res }}$, and $\Delta T$ enables a broad definition of the main chemical activity regions. It is evident that ignition is observed regardless of residence time values for temperatures higher than $900 \mathrm{~K}$ and inlet fuel mass fractions lower than 0.2 . When sufficient time is available $\left(t_{\text {res }}=0.1 \mathrm{~s}\right)$, ignition may also occur at slightly lower inlet temperatures $\left(T_{\text {in }}=860 \mathrm{~K}\right)$. On the other hand, cool flame activity extends to a broad region, spanning a much wider range of the investigated parameter space. Cool flame activity is favoured in fuel-rich conditions; the respective temperature region is increased with increasing inlet fuel concentration. In addition, increasing the residence time results in extending the temperature region where cool flame reactions emerge.

The developed tool is validated on the basis of experimental observations in a stabilized cool flame reactor [51]. Edenhofer et al. [51] have constructed a thermochemical behaviour map of their reactor (c.f. Figure 2 of [51]) using 4 different reaction "regimes," namely, the "no reaction" regime, the "cool flame" regime (corresponding to outlet temperatures up to $740 \mathrm{~K}$ ), the "slow oxidation" regime (outlet temperatures up to $875 \mathrm{~K}$ ), and the "ignition" regime (outlet temperatures over $1300 \mathrm{~K}$ ). The outlet temperature criteria used in [51] have been applied to formulate Figure 13, where predictions of the developed tool are classified into the same 4 different reaction regimes. Numerical predictions achieve, both qualitatively and quantitatively, a good level of agreement with available experimental data [51]; the dashed line in Figure 13 corresponds to the operational conditions presented in [51].

\section{Conclusions}

A tabulated chemistry tool, capable of simulating the thermochemical behaviour of n-heptane oxidation in the low-, intermediate-, and high-temperature regimes, has been developed. n-Heptane has been used as a surrogate fuel of diesel oil. Extensive numerical simulations have been performed, using a detailed n-heptane oxidation chemical kinetic mechanism and utilizing the perfectly stirred reactor assumption. Three independent parameters have been varied in order to construct the chemical database: inlet temperature, inlet fuel concentration, and residence time. The comprehensive parametric analysis of the obtained predictions, that is, heat release, outlet temperature, species production and consumption rates, species mole fractions, and so forth, allowed the comparative assessment of the impact of the varying variables on the thermochemical behaviour of $n$ heptane.

Two main chemical activity regimes appear in all cases; the conventional "ignition" region emerges at temperatures higher than $880 \mathrm{~K}$, whereas the "cool flame" oxidation region extends approximately between $620 \mathrm{~K}$ and $800 \mathrm{~K}$. Increasing the fuel concentration favours cool flame activity; the respective temperature region is extended and the peak heat release is increased. In addition, when the residence time is increased, the temperature region of the cool flame regime is significantly extended and the maximum heat release value is "shifted" towards lower temperatures; however, residence time variations slightly affect the characteristics of the ignition regime. Rate of production and sensitivity analyses have been also performed, aiming to elucidate the different chemical paths prevailing in each oxidative region. Competition between the endothermic decomposition and the exothermic isomerization reactions of C7 alkylperoxy species appear to largely determine overall system reactivity in the cool flame regime. Finally, the obtained predictions have been used to develop an indicative thermochemical behaviour "map," which assists in the estimation of the expected oxidation regime (e.g., cool flame or ignition) in technical devices.

\section{Conflict of Interests}

The authors declare that there is no conflict of interests regarding the publication of this paper.

\section{Acknowledgments}

This work has been partly performed in the framework of the CM0901 COST action "Detailed Chemical Kinetic Models for Cleaner Combustion." Financial support through the FCDistrict (Grant no. 260105) and the ECCO-MATE (Grant no. 607214) EU research projects is acknowledged.

\section{References}

[1] T. Lu and C. K. Law, "Toward accommodating realistic fuel chemistry in large-scale computations," Progress in Energy and Combustion Science, vol. 35, no. 2, pp. 192-215, 2009. 
[2] F. Battin-Leclerc, "Detailed chemical kinetic models for the low-temperature combustion of hydrocarbons with application to gasoline and diesel fuel surrogates," Progress in Energy and Combustion Science, vol. 34, no. 4, pp. 440-498, 2008.

[3] C. K. Westbrook and F. L. Dryer, "Chemical kinetic modeling of hydrocarbon combustion," Progress in Energy and Combustion Science, vol. 10, no. 1, pp. 1-57, 1984.

[4] H. Machrafi, S. Cavadias, and J. Amouroux, "Influence of fuel type, dilution and equivalence ratio on the emission reduction from the auto-ignition in an Homogeneous Charge Compression Ignition engine," Energy, vol. 35, no. 4, pp. 18291838, 2010.

[5] D. Ganesh and G. Nagarajan, "Homogeneous charge compression ignition (HCCI) combustion of diesel fuel with external mixture formation," Energy, vol. 35, no. 1, pp. 148-157, 2010.

[6] S. Cong, G. P. McTaggart-Cowan, C. P. Garner, E. Wahab, and M. Peckham, "Experimental investigation of low temperature diesel combustion processes," Combustion Science and Technology, vol. 183, no. 12, pp. 1376-1400, 2011.

[7] Y. Ohkubo, Y. Idota, and Y. Nomura, "Evaporation characteristics of fuel spray and low emissions in a lean premixedprevaporization combustor for a $100 \mathrm{~kW}$ automotive ceramic gas turbine," Energy Conversion and Management, vol. 38, pp. 1297-1309, 1997.

[8] T. B. Gradinger, A. Inauen, R. Bombach, B. Käppeli, W. Hubschmid, and K. Boulouchos, "Liquid-fuel/air premixing in gas turbine combustors: experiment and numerical simulation," Combustion and Flame, vol. 124, no. 3, pp. 422-443, 2001.

[9] L. Hartmann, K. Lucka, and H. Köhne, "Mixture preparation by cool flames for diesel-reforming technologies," Journal of Power Sources, vol. 118, no. 1-2, pp. 286-297, 2003.

[10] A. Naidja, C. R. Krishna, T. Butcher, and D. Mahajan, "Cool flame partial oxidation and its role in combustion and reforming of fuels for fuel cell systems," Progress in Energy and Combustion Science, vol. 29, no. 2, pp. 155-191, 2003.

[11] J. Matos da Silva, I. Hermann, C. Mengel, K. Lucka, and H. Köhne, "Autothermal reforming of gasoline using a cool flame vaporizer," AIChE Journal, vol. 50, no. 5, pp. 1042-1050, 2004.

[12] E. J. D'Onofrio, "Cool flame and autoignition in glycols," Journal of Loss Prevention in the Process Industries, vol. 13, pp. 89-97, 1979.

[13] A. A. Pekalski and H. J. Pasman, "Distinction between the upper explosion limit and the lower cool flame limit in determination of flammability limit at elevated conditions," Process Safety and Environmental Protection, vol. 87, no. 1, pp. 47-52, 2009.

[14] P. G. Lignola and E. Reverchon, "Cool flames," Progress in Energy and Combustion Science, vol. 13, no. 1, pp. 75-96, 1987.

[15] J. F. Griffiths, "Reduced kinetic models and their application to practical combustion systems," Progress in Energy and Combustion Science, vol. 21, no. 1, pp. 25-107, 1995.

[16] A. J. Harrison and L. R. Cairnie, "The development and experimental validation of a mathematical model for predicting hot-surface autoignition hazards using complex chemistry," Combustion and Flame, vol. 71, no. 1, pp. 1-21, 1988.

[17] P. Dagaut, M. Reuillon, and M. Cathonnet, "Experimental study of the oxidation of $n$-heptane in a jet stirred reactor from low to high temperature and pressures up to 40 Atm," Combustion and Flame, vol. 101, no. 1-2, pp. 132-140, 1995.

[18] R. S. Sheinson and F. W. Williams, "Chemiluminescence spectra from cool and blue flames: electronically excited formaldehyde," Combustion and Flame, vol. 21, no. 2, pp. 221-230, 1973.
[19] M. J. Pilling, Ed., Low-Temperature Combustion and Autoignition, vol. 35 of Comprehensive Chemical Kinetics, Elsevier, Amsterdam, The Netherlands, 1997.

[20] K. Lucka and H. Koehne, "Usage of cold flames for the evaporation of liquid fuels," in Proceedings of the 5th International Conference on Clean Air Technology, pp. 207-213, Lisbon, Portugal, 1999.

[21] H. J. Curran, P. Gaffuri, W. J. Pitz, and C. K. Westbrook, "A comprehensive modeling study of n-heptane oxidation," Combustion and Flame, vol. 114, no. 1-2, pp. 149-177, 1998.

[22] H. J. Curran, P. Gaffuri, W. J. Pitz, and C. K. Westbrook, "A comprehensive modeling study of iso-octane oxidation," Combustion and Flame, vol. 129, no. 3, pp. 253-280, 2002.

[23] E. Ranzi, P. Gaffuri, T. Faravelli, and P. Dagaut, "A widerange modeling study of $\mathrm{n}$-heptane oxidation," Combustion and Flame, vol. 103, no. 1-2, pp. 91-106, 1995.

[24] D. I. Kolaitis and M. A. Founti, "On the assumption of using nheptane as a "surrogate fuel" for the description of the cool flame oxidation of diesel oil," Proceedings of the Combustion Institute, vol. 32, pp. 3197-3205, 2009.

[25] P. Zhao and C. K. Law, "The role of global and detailed kinetics in the first-stage ignition delay in NTC-affected phenomena," Combustion and Flame, vol. 160, no. 11, pp. 2352-2358, 2013.

[26] C. K. Law and P. Zhao, "NTC-affected ignition in nonpremixed counterflow," Combustion and Flame, vol. 159, no. 3, pp. 10441054, 2012.

[27] D. M. A. Karwat, S. W. Wagnon, M. S. Wooldridge, and C. K. Westbrook, "Low-temperature speciation and chemical kinetic studies of n-heptane," Combustion and Flame, vol. 160, pp. 2693-2706, 2013.

[28] O. Herbinet, B. Husson, Z. Serinyel et al., "Experimental and modeling investigation of the low-temperature oxidation of $n$ heptane," Combustion and Flame, vol.159, no. 12, pp. 3455-3471, 2012.

[29] S. K. Aggarwal, "A review of spray ignition phenomena: present status and future research," Progress in Energy and Combustion Science, vol. 24, no. 6, pp. 565-600, 1998.

[30] A. Cuoci, M. Mehl, G. Buzzi-Ferraris, T. Faravelli, D. Manca, and E. Ranzi, "Autoignition and burning rates of fuel droplets under microgravity," Combustion and Flame, vol. 143, no. 3, pp. 211-226, 2005.

[31] O. Colin, A. P. da Cruz, and S. Jay, "Detailed chemistry-based auto-ignition model including low temperature phenomena applied to 3-D engine calculations," Proceedings of the Combustion Institute, vol. 30, pp. 2649-2656, 2005.

[32] M. A. Founti and D. I. Kolaitis, "Numerical simulation of diesel spray evaporation exploiting the "stabilized cool flame" phenomenon," Atomization and Sprays, vol. 15, no. 1, pp. 1-18, 2005.

[33] D. I. Kolaitis and M. A. Founti, "Numerical modelling of transport phenomena in a diesel spray "stabilized cool flame" reactor," Combustion Science and Technology, vol. 178, no. 6, pp. 1087-1115, 2006.

[34] D. I. Kolaitis and M. A. Founti, "A tabulated chemistry approach for numerical modeling of diesel spray evaporation in a "stabilized cool flame" environment," Combustion and Flame, vol. 145, no. 1-2, pp. 259-271, 2006.

[35] D. I. Katsourinis and M. A. Founti, "CFD modelling of a "stabilized cool flame" reactor with reduced mechanisms and a direct integration approach," Chemical Engineering Science, vol. 63, no. 2, pp. 424-433, 2008. 
[36] J. J. Hernandez, J. Sanz-Argent, J. Benajes, and S. Molina, "Selection of a diesel fuel surrogate for the prediction of autoignition under HCCI engine conditions," Fuel, vol. 87, no. 6, pp. 655-665, 2008.

[37] W. J. Pitz and C. J. Mueller, "Recent progress in the development of diesel surrogate fuels," Progress in Energy and Combustion Science, vol. 37, no. 3, pp. 330-350, 2011.

[38] F. Tao, V. I. Golovitchev, and J. Chomiak, "Self-ignition and early combustion process of $n$-heptane sprays under diluted air conditions: numerical studies based on detailed chemistry," Society of Automotive Engineers Paper 2000-01-2931, SAE Transactions, 2000.

[39] H. K. Ciezki and G. Adomeit, "Shock-tube investigation of self-ignition of n-heptane-air mixtures under engine relevant conditions," Combustion and Flame, vol. 93, no. 4, pp. 421-433, 1993.

[40] A. J. Donkerbroek, A. P. van Vliet, L. M. T. Somers et al., "Time- and space-resolved quantitative LIF measurements of formaldehyde in a heavy-duty diesel engine," Combustion and Flame, vol. 157, no. 1, pp. 155-166, 2010.

[41] A. J. Donkerbroek, A. P. van Vliet, L. M. T. Somers, N. J. Dam, and J. J. ter Meulen, "Relation between hydroxyl and formaldehyde in a direct-injection heavy-duty diesel engine," Combustion and Flame, vol. 158, no. 3, pp. 564-572, 2011.

[42] N. A. Slavinskaya and O. J. Haidn, "Modeling of n-heptane and iso-octane oxidation in air," Journal of Propulsion and Power, vol. 19, no. 6, pp. 1200-1216, 2003.

[43] Y. Muharam and J. Warnatz, "Kinetic modelling of the oxidation of large aliphatic hydrocarbons using an automatic mechanism generation," Physical Chemistry Chemical Physics, vol. 9, no. 31, pp. 4218-4229, 2007.

[44] M. Chaos, A. Kazakov, Z. Zhao, and F. L. Dryer, "A hightemperature chemical kinetic model for primary reference fuels," International Journal of Chemical Kinetics, vol. 39, no. 7, pp. 399-414, 2007.

[45] T. Zeuch, G. Moréac, S. S. Ahmed, and F. Mauss, "A comprehensive skeletal mechanism for the oxidation of $n$-heptane generated by chemistry-guided reduction," Combustion and Flame, vol. 155, no. 4, pp. 651-674, 2008.

[46] A. M. Kanury, Introduction to Combustion Phenomena, Gordon and Breach Science Publishers, 1994.

[47] N. Peters, Turbulent Combustion, Cambridge University Press, 2000.

[48] S. C. Kong, C. D. Marriott, R. D. Reitz, and M. Christensen, "Modeling and experiments of HCCI engine combustion using detailed chemical kinetics with multidimensional CFD," Tech. Rep. 2001-01-1026, SAE Transactions, 2001.

[49] R. J. Kee, F. M. Rupley, J. A. Miller et al., CHEMKIN Collection, Release 4. 1, Reaction Design, San Diego, Calif, USA, 2007.

[50] N. Steinbach, Untersuchungen zum Zuendverhalten von Heizoel EL-Luft-Gemischen unter atmosphaerischem Druck [Ph.D. thesis], RWTH , Aachen, Germany, 2002.

[51] R. Edenhofer, K. Lucka, and H. Kohne, "Low temperature oxidation of diesel-air mixtures at atmospheric pressure," Proceedings of the Combustion Institute, vol. 31, pp. 2947-2954, 2007.

[52] S. W. Benson, "The kinetics and thermochemistry of chemical oxidation with application to combustion and flames," Progress in Energy and Combustion Science, vol. 7, no. 2, pp. 125-134, 1981.

[53] A. Kazakov, M. Chaos, Z. Zhao, and F. L. Dryer, "Computational singular perturbation analysis of two-stage ignition of large hydrocarbons," Journal of Physical Chemistry A, vol. 110, no. 21, pp. 7003-7009, 2006. 

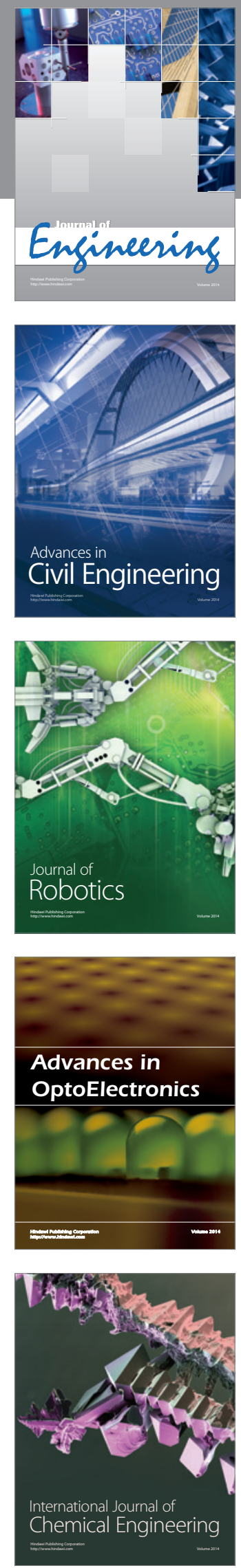

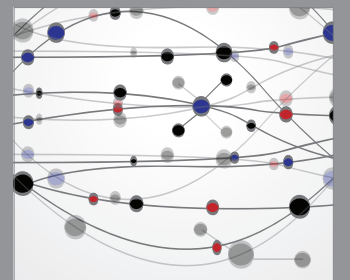

The Scientific World Journal
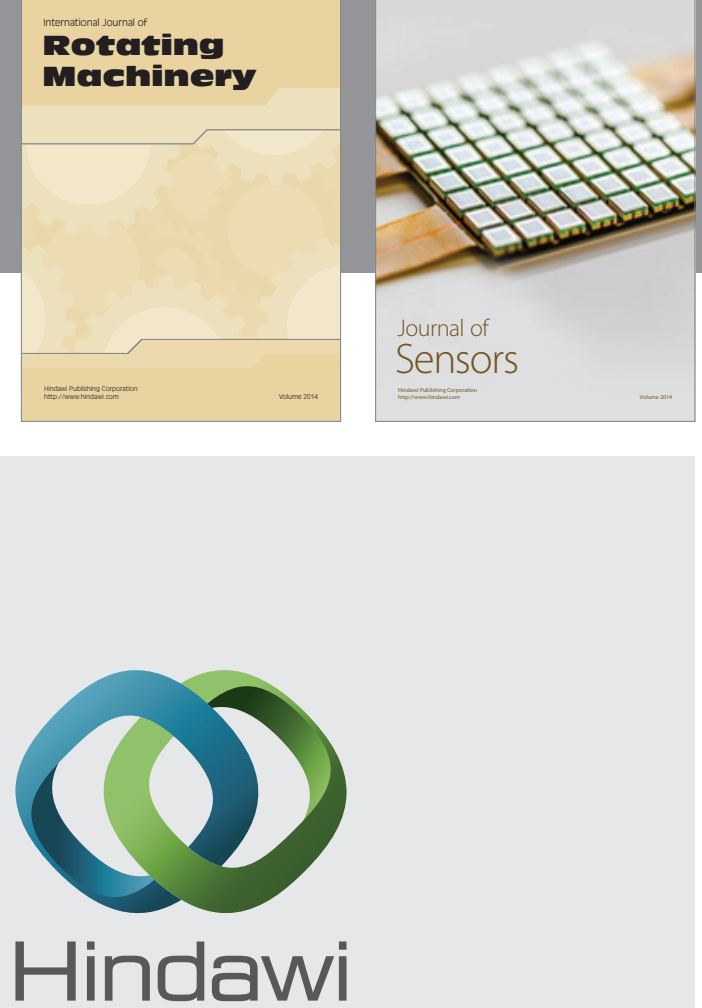

Submit your manuscripts at http://www.hindawi.com
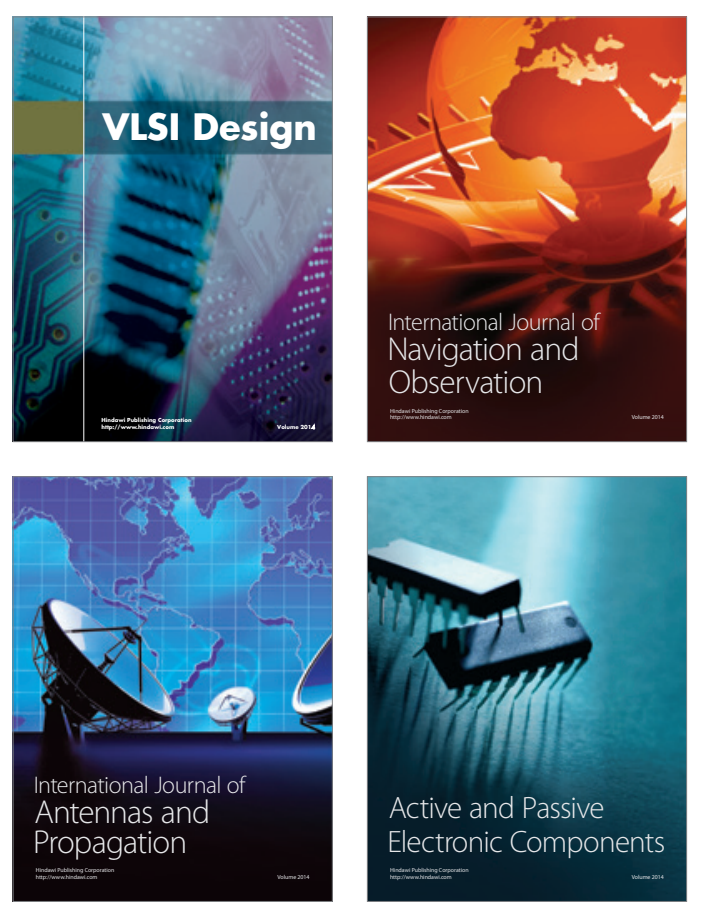
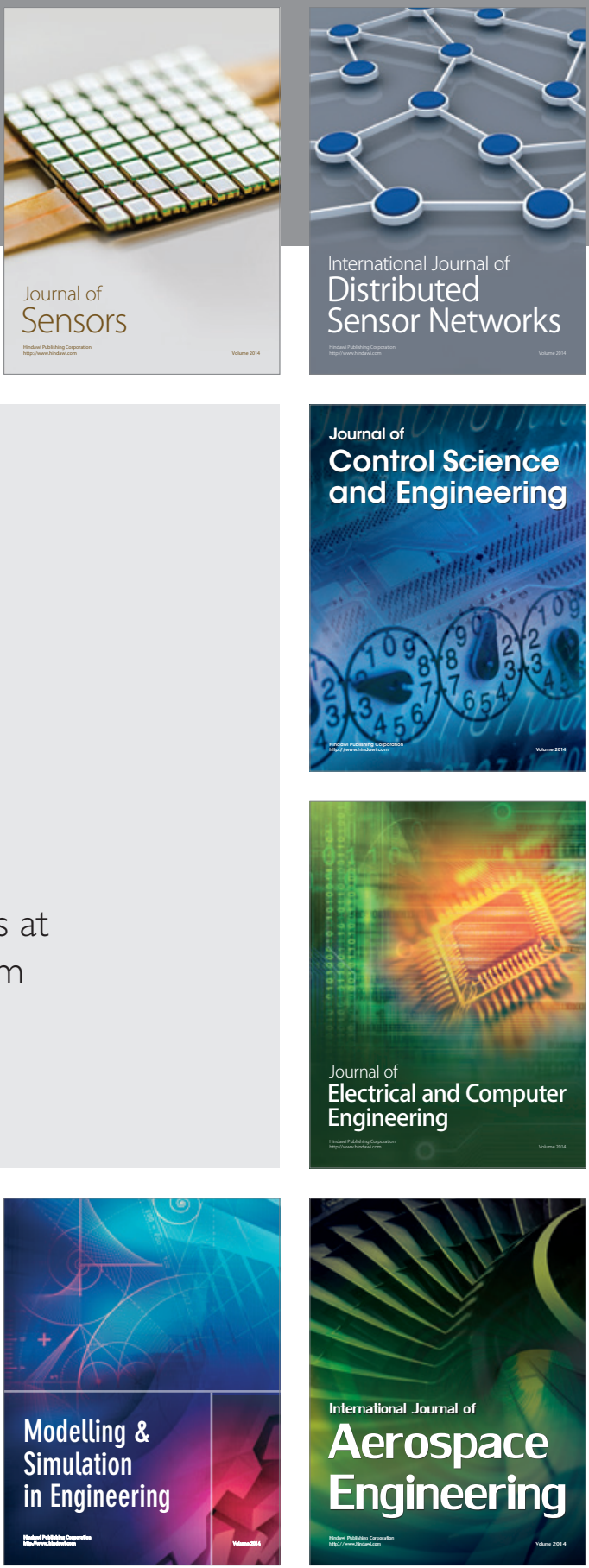

Journal of

Control Science

and Engineering
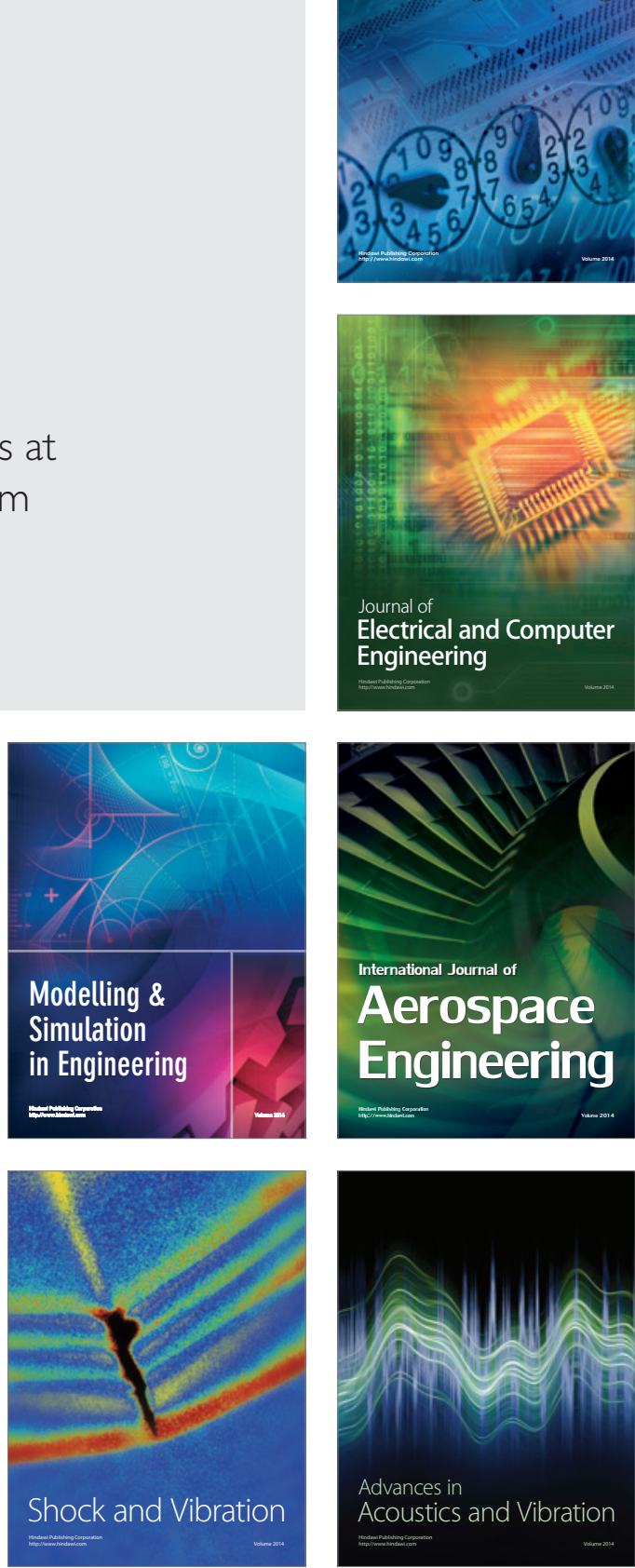